\title{
LA PRUEBA CIENTIFICA ${ }^{1}$
}

\section{THE CIENTIFIC EVIDENCE}

\section{Adrián Simons Pino}

Abogado, Miembro del Instituto Iberoamericano de Derecho

Procesal, Miembro de la Asociación Internacional de

Derecho Procesal, Miembro de la Asociación

Latinoamericana de Arbitraje. Profesor de la Academia de la Magistratura. Perú. adrian.simons@simonsabogados.com

RESUMO: o artigo trata da prova científica, que é uma variante da prova pericial. Aquela engloba, por exemplo, a prova pericial propriamente dita, oitiva de peritos ou de especialistas. Sustentamos neste texto que a alta confiabilidade da prova científica não se confunde com a sua infalibidade. Cabe ao juiz ou árbitro atuar como o guardião da prova científica, visando evitar que, no processo, ingressem provas sem idoneidade, valorando de maneira adequada a validade do método utilizado, bem como a margem de erro deste. Para tanto, o Daubert Case, julgado pela Suprema Corte norte-americana em 1993, pode ser utilizado como parâmetro a ser assimilado pela jurisprudência e as legislações nacionais. Assim, mostra-se necessária uma nova regulamentação em matéria de prova pericial, bem como, enquanto as legislações não sofrem as alterações necessárias, os juízes devem adequar os procedimentos aos novos requerimentos de prova.

PALAVRAS-CHAVE: prova pericial; Daubert case; poderes instrutórios; fontes de prova.

ABSTRACT: The article deals with the scientific proof, which is a variant of expert evidence. This includes, for example, expert evidence, expert testimony or experts. We maintain in this text that the high reliability of the scientific evidence is not confused with its infallibility. It is up to the judge or arbitrator to act as the guardian of the scientific evidence, in order to avoid that in the process, they enter evidence without suitability,

\footnotetext{
${ }^{1}$ Artigo recebido em 08/09/2017, sob dispensa de revisão.
} 
valuing in an appropriate way the validity of the method used, as well as the margin of error of this one. To this end, the Daubert Case, judged by the US Supreme Court in 1993, can be used as a parameter to be assimilated by the jurisprudence and the national legislations. Thus, new rules on expert evidence are necessary and, as long as the legislation does not suffer the necessary changes, the judges must adapt the procedures to the new evidence requirements.

KEYWORDS: Expert evidence; Daubert case; instructional powers; sources of evidence.

\section{"Una vida sin ciencia es como una vida sin música",}

\section{I. ¿LA SOCIEDAD DEL CONOCIMIENTO?}

Como ha indicado el científico español Peré Estupinyá "la ciencia son las gafas que nos permiten escudriñar en la estructura del universo, descubrir el mundo microscópico, explorar el interior del cerebro humano, comprender nuestro comportamiento, y disfrutar de toda la complejidad y esplendor que oculta la naturaleza"3.

Por ejemplo, una gran revolución llegó con la capacidad de observar el funcionamiento del cerebro en tiempo real, a través de lo que ahora se llama Neurociencia. Más allá de las aplicaciones médicas, los Scaners de Resonancia Magnética Funcional están siendo utilizados para investigar lo más profundo de nuestra personalidad. El futuro ya está presente!

Los científicos ya están afirmando que las imágenes más precisas de la actividad cerebral, pueden ser utilizadas para exculpar a alguien de un proceso si se detectan que las fechorías no son atribuibles a la voluntad de esa persona, sino debido a una programación cerebral defectuosa. Esto puede llevar a revolucionar las bases del derecho penal y los principios que sostienen a la imputación.

Ahora, se sabe, que los escáneres de resonancia magnética funcional pueden detectar las alteraciones en los cerebros de los pederastas. Incluso un grupo de científicos de la

\footnotetext{
${ }^{2}$ ESTUPINYÁ, Pere. El ladrón de cerebros. Compartiendo el conocimiento científico de las mentes más brillantes. DEBOLSILLO, Barcelona, 2013, p. 20

${ }^{3}$ ESTUPINYÁ, Pere. El ladrón de cerebros. Ob. cit. p.20.
} 
Universidad de Harvard, ha planteado válidamente la siguiente pregunta: ¿debería ser reconsiderada la ley criminal en vista de los avances de la neurociencia?

Hemos llegado a tal punto que el principio de autoridad y el sentido común no se llevan muy bien con la ciencia. La ciencia nos enseña que la toma de decisiones debe estar basada en evidencia y corregir constantemente nuestras creencias cuando las evidencias de la experimentación nos lo sugieren.

A partir de ahora, el sentido común ya no será el mismo. Y, nuestras máximas de experiencia, deberán tener otro estándar.

Los jueces de muchas partes del mundo ya son conscientes de ello. Pero, llevar el mundo del conocimiento científico al proceso (sea judicial o arbitral) no será tarea fácil. Veamos.

\section{LOS CASOS DAUBERT-JOINER-KUMHO ${ }^{4} 67$.}

Hoy en día, no se puede hablar de la prueba científica sin hacer referencia a la llamada trilogía DAUBERT-JOINER-KUMHO.

Antes de estos casos emblemáticos, el referente era el caso FRYE vs USA de 1923. La Corte Suprema de los Estados Unidos, descartó como prueba pericial científica el detector de mentiras basado en la presión arterial sistólica. La doctrina derivada del caso FRYE estableció que los métodos usados por el experto para formar sus conclusiones científicas, deberían encontrarse entre los generalmente aceptados por la comunidad científica especializada. Apreciemos que, desde 1923, la Corte Suprema de los Estados Unidos mostró una preocupación por la ciencia y su influencia en el proceso. En las

\footnotetext{
${ }^{4}$ PEREZ GIL, Julio. El Conocimiento Científico en el Proceso Civil, Tirant lo Blanch, Valencia, 2010, pp. $102,103,104,105,106$ y 107.

${ }^{5}$ TARUFFO, Michele. La Prueba. Marcial Pons, Madrid, 2008, pp. 90, 94, 95,97, 98, 99 y 100.

${ }^{6}$ LLUCH, Xavier Abel. La Valoración de la Prueba Científica. En: Derecho Probatorio Contemporáneo. Prueba Científica y Técnicas Forenses. Coordinadora: BUSTAMANTE RÚA, Mónica María, Universidad de Medellín, Fundación Universitaria Tecnológico Comfenalco, Colombia, 2012, p. 244.

${ }^{7}$ SANDERS, Joseph. La paradoja de la relación metodología y conclusión y la estructura de la decisión judicial en los Estados Unidos. En: Derecho Probatorio Contemporáneo. Prueba Científica y Técnicas Forenses. Coordinadora: BUSTAMANTE RÚA, Mónica María, Universidad de Medellín, Fundación Universitaria Tecnológico Comfenalco, Colombia, 2012, pp.99, 100, 101, 102, 103, 104, 105, 106, 107, 108 y 109.
} 
siguientes líneas haré una breve síntesis de los casos que consagraron esa justificada preocupación.

\section{CASO DAUBERT vS MERREL DOW PHARMACEUTICALS INC} (1993):

Se trataba de un fármaco llamado Bendictin que se recetaba para las náuseas de las mujeres embarazadas. Los demandantes, argumentaron que la medicina causaba defectos de nacimiento en los recién nacidos.

Tanto en primera, como segunda instancia, había mucha evidencia epidemiológica en contra de lo indicado en el dictamen pericial (aplicaron la regla FRYE).

El caso llegó hasta la Corte Suprema de los Estados Unidos, y ésta revocó la decisión de la Corte del Noveno Circuito de Apelaciones, declarando que ya no era aplicable la REGLA FRYE, en materia de prueba científica.

Fue la primera vez que una Corte Suprema, de un ordenamiento jurídico importante, asumió el problema de la validación científica de nociones extrajurídicas de las cuales el juez puede servirse para fundamentar su decisión.

El juez ponente Blackmun, como lo refirió el profesor Taruffo, creó un mini tratado de epistemología, en el que se hizo prevalecer el conocimiento reflexivo elaborado con rigor, frente al doxa, que hasta ese momento representaba al conocimiento ordinario sin rigurosa reflexión. Para tal efecto, el juez Blackmun creó una lista de criterios para la admisión y valoración de la evidencia científica o técnica que se haya aportado al proceso. Ahora bien, esa lista no debe ser apreciada como una de carácter cerrado, todo lo contrario, debe permanecer abierta para que los jueces o árbitros puedan emplear criterios complementarios, en consonancia con los avances de la ciencia o tecnología.

\section{CRITERIOS:}


PRIMER CRITERIO: FALSABILIDAD (FALSIABILITY): Se manifiesta con la siguiente pregunta: ¿La prueba se basa en una teoría o una técnica susceptible de contraste? Esto tiene que ver con el control empírico de la teoría o técnica usada para la producción de la prueba aportada al proceso.

\section{SEGUNDO CRITERIO: REVISIÓN POR PARES (PEER REVIEW): Se} manifiesta haciendo la siguiente pregunta: ¿Ha sido la teoría o técnica revisada por otros científicos o técnicos?

La revisión científica se considera como necesaria para la defensa de la "buena ciencia" y el imprescindible descarte de la "mala ciencia" o también llamada "ciencia basura" (junk science), por cuanto incrementa las posibilidades de detección de errores metodológicos. Por ejemplo, la publicación de los resultados de una investigación en revistas científicas o especializadas de reconocido prestigio, es un ingrediente que debe incrementar la confianza en el juez, respecto de la validez o confiabilidad del método utilizado por el experto o perito. Todo juez debe ser cuidadoso cuando tiene frente así una prueba catalogada como científica o técnica, porque puede tratarse de un lobo feroz disfrazado de caperucita; por ejemplo, cuando se está frente a una prueba de ADN realizada por un laboratorio que no tiene certificaciones o, si las tuviera, no son las adecuadas, o si la muestra tomada no fue la requerida, o si esta no fue objeto de una adecuada conservación antes de ser llevada para análisis, etc.

Pero, también hay que reconocer que, en algunos casos, los descubrimientos científicos o técnicos pueden ser innovadores o singulares, o de un interés específico para haber sido objeto de alguna publicación de manera periódica o reiterada. Esta situación debe ser apreciada por el juez o árbitro según el caso concreto.

TERCER CRITERIO: PORCENTAJE DE ERROR CONOCIDO O POTENCIAL (STANDAR AND ERROR RATES): ¿Cuenta la técnica con una tasa de error conocido y con normas de control de su operatividad? ¿Respeta los estándares de 
correcta ejecución en las operaciones aplicativas? Esto responde al conocimiento de la probabilidad efectiva o potencial de error.

\section{CUARTO CRITERIO: CONSENSO GENERAL DE LA COMUNIDAD} CIENTÍFICA (GENERAL ACCEPTANCE): ¿La ciencia utilizada es generalmente aceptada? Si bien este es el mismo criterio que el asumido en el caso FRYE, al ponerse en contexto con todos los demás criterios adquiere una dimensión absolutamente diversa.

\section{PROBLEMAS ESENCIALES POSTULADOS EN EL CASO DAUBERT:}

PRIMERO: La necesidad de que el conocimiento extrajudicial del cual el juez se sirve para decidir sobre los hechos, sea científicamente válido.

SEGUNDO: Se espera que el juez sea una especie de guardián o gatekeeper de la prueba científica, que tenga la potestad de seleccionar y admitir para valoración al momento de resolver, sólo la prueba científicamente válida.

TERCERO: Se pone en crisis el mito según el cual la ciencia sería capaz de encontrar la verdad cierta e indiscutible. Este mito favorecería una dirección pasiva y sometida de los jueces sobre lo que dicen los científicos, técnicos, expertos o peritos. Mito que muchas veces se ve reforzado por la presión mediática cuando se trata de un caso de interés público, en el que se ha puesto en evidencia alguna pericia o dictamen científicotécnico que, a su vez, sirve de pretexto para los denominados "juzgamientos o linchamientos públicos" sobre la inocencia o culpabilidad de una persona.

Ocurre a menudo que en el proceso se discuten técnicas de indagación que se definen como científicas, pero que en muchos casos no lo son, con el consecuente riesgo de cometer graves errores en la confirmación de los hechos. Solo un juez, actuando como epistemólogo y aplicando los criterios antes indicados, puede llegar a conclusiones válidas al momento de valorar la prueba. 


\section{CASO JOINER vS GENERAL ELECTRIC (1996).}

En este caso el demandante alegó que adquirió un cáncer al pulmón por su exposición al PCB’S (bifenilos policrorinados), que se usaba como aislante para equipos eléctricos. Esta es una sustancia tóxica y está considerada como uno de los doce contaminantes más nocivos.

El demandante era un fumador y con antecedentes familiares de cáncer al pulmón, pero argumentó que el PCB'S desencadenó o activó su cáncer.

El juez supremo Rehnquist revisó los estudios científicos presentados por el demandante y aplicando las reglas del caso DAUBERT, concluyó que no había relación que estadísticamente lo demostrase. Se presentaron estudios de trabajadores de una planta del Estado de Illinois que acreditaban una alta incidencia de muertes por cáncer al pulmón. Sin embargo, ese incremento no fue estadísticamente significativo. Los expertos no pudieron concluir y vincular el aumento de las muertes por cáncer al pulmón, con la exposición a los $\mathrm{PCB}^{\prime} \mathrm{S}$.

\section{CASO KUMHO TIRE vS CARMICHAEL (1999).}

La Corte Suprema decidió revisar nuevamente el tema, porque la Corte del Décimo Primer Circuito de Apelaciones sostuvo que la regla de la admisibilidad de DAUBERT se aplicaba sólo a la prueba científica, y no a otros tipos de pruebas periciales.

En este caso, los demandantes resultaron heridos cuando el neumático trasero derecho de su camioneta estalló. Por ende, alegaron que los neumáticos Kumho tenían algún defecto de fabricación.

Así concluyó el perito o experto de los demandantes: "la carcasa del neumático debe permanecer unida a la parte interna de la banda de rodamiento por un periodo significativo de tiempo, después del natural desgaste de su banda de rodamiento". En el caso, la banda de rodamiento se separó de su interior con cinturón de acero. El experto, para emitir su dictamen realizó una inspección visual y táctil de la cubierta del neumático, y constató que 
no había sufrido sobredesviación (desinflamiento o demasiado peso); por tanto, concluyó que la llanta estaba defectuosa.

La Corte de Apelaciones indicó que dicha inspección no puede ser considerada como un dictamen de un experto científico y por lo tanto no aplicó la regla DAUBERT.

La Corte Suprema expresó su discrepancia y corrigiendo la decisión anterior, determinó que sí debe aplicarse dicha regla. Indicó que el método usado fue confiable, pero su aplicación al caso concreto no lo fue, porque el informe también indicaba que la llanta tenía un gran desgaste en la banda de rodamiento (como lo relató claramente Joseph Sanders al comentar el caso). En tal caso, podría decirse que bajo el criterio establecido la opinión del experto si bien no calificaba como una prueba científica, tal vez, podría ser considerada como una prueba técnica susceptible de ser controlada bajo los criterios jurisprudenciales antes referidos.

\section{IMPACTO DE ESTAS SENTENCIAS.}

1. Sus efectos fueron seguidos en la mayoría de las cortes federales y estatales.

2. En el año 2000 el legislador norteamericano modificó el artículo $702^{\circ}$ de las Federal Ruls of Evidence, para incorporar los criterios establecidos en las sentencias de los casos DOUBERT - JOINER - KUMHO.

3. Con la modificación establecida, la Regla $702^{\circ}$ quedó redactada de la siguiente manera: "Cuando los conocimientos científicos, técnicos u otros especializados puedan servir al Jurado para entender las pruebas o fijar los hechos del caso, podrá tenerse en cuenta el testimonio de un experto por razón de conocimiento, habilidad, experiencia, formación o educación en el que exprese su opinión si (1) el testimonio está suficientemente fundado en hechos o datos fiables, (2) el testimonio es producto de principios y métodos fiables, y (3) el testigo aplica los principios y métodos a los hechos del caso de forma fiable". 
4. Es importante precisar que el "testigo experto" (witness expert) es el equivalente en nuestro sistema al perito. En Inglaterra, tiene una regulación especial, la cual otorga al juez un poder de control respecto de la prueba pericial que se vaya a ofrecer. Es decir, para el ejercicio de tal medio probatorio se requiere la conformidad de la Corte.

5. La influencia de las indicadas sentencias trascendió continentes y llegó hasta nuestro sistema (civil law). La doctrina fijada por los tribunales norteamericanos sobre el llamado "juicio de admisibilidad" de las pruebas científicas, es hoy imprescindible para cualquier aproximación al tema. Ese reconocimiento pacífico, que supera las barreras tradicionales entre los sistemas del civil law y el common law, se debe probablemente a una necesidad compartida: la de afrontar el problema de discernir entre la buena ciencia y la que solo tiene una mera apariencia de serlo. Además, de poner en manos del juez o árbitro, una serie de herramientas para evaluar la fiabilidad de la prueba científica o técnica aportada por alguna de las partes.

6. Como indicó Julio Perez $\mathrm{Gil}^{8}$, una correcta aplicación de los requerimientos derivados del caso DAUBERT va dirigida a establecer con carácter previo al juicio, lo que pudiera ser calificado como una aceptable "verdad científica".

7. El caso DAUBERT, trajo un desarrollo de determinados conceptos referidos a la prueba científica o técnica y su aporte al proceso, como instrumento efectivo de comprobación de los hechos invocados por las partes. Aumentando el grado de certeza o veracidad de la decisión. Teniendo en cuenta ello, en las siguientes líneas veremos, bajo la perspectiva del profesor Taruffo $^{9}$, una clasificación de las ciencias que nos permitirá apreciar mejor el rol del juez al momento de la admisión, actuación y valoración de las pruebas científicas o técnicas.

\section{CLASIFICACIÓN DE LAS CIENCIAS.}

\footnotetext{
${ }^{8}$ PEREZ GIL, Julio. El Conocimiento científico en el proceso civil, ob.cit., p. 107.

${ }^{9}$ TARUFFO, Michele. La Prueba, ob. cit., p. 97.
} 
A) Ciencias Empíricas: son las ciencias de la explicación y dentro las cuales resaltan las ciencias naturales; las llamadas ciencias duras (química, física, biología, genética, determinadas ramas de la ingeniería, matemáticas -aunque no tiene base empírica).

B) Ciencias Sociales: son las ciencias apreciadas desde la comprensión, también llamadas ciencias del espíritu, humana o social (psicología, sociología, antropología, historia, derecho, etc.). Se puede decir que son todas las que estudian el comportamiento humano.

Sé que catalogar a las ciencias en dos grupos puede ser calificado como osado, pero tiene una función didáctica para resaltar la base empírica y social que les sirve como fuente de comprobación. Por ejemplo, hay ciencias que no podrían ser calificadas como enteramente empíricas o sociales como la economía y la contabilidad. La economía puede tener una dimensión matemática o numérica, pero también tiene en consideración los comportamientos sociales frente a los fenómenos de producción, o la relación del hombre con la propiedad o la riqueza.

Lo relevante es que sin importar el tipo de ciencia, la actitud del juez o árbitro debe ser como la de un epistemólogo; y lo más recomendable, al momento de sustentar su decisión sobre la base de la evidencia científica aportada, es que aplique los estándares de fiabilidad antes mencionados.

El uso de nuevos estándares de control de fiabilidad de la prueba científica, trajo como consecuencia una serie de cuestionamientos frente a determinadas técnicas que antes gozaban de un alto grado de confiabilidad. En el año 2009, la National Academy of Science en una publicación titulada "Strengthening Forensic Sciencies in the United States", se cuestionaron las 12 principales técnicas forenses desde el punto de vista de la severidad científica. Todas las técnicas forenses, con excepción de los test genéticos, son cuestionadas respecto del fundamento de su absoluta validez científica. Esto afectó a las técnicas más usadas: huellas digitales, pericia caligráfica y pericia balística.

El principal argumento que se planteó para justificar tales estudios, relativos a la falta de certeza científica, radica en que estas técnicas tienen una valoración subjetiva por parte de los expertos que las usan. La consecuencia es que si dos expertos llegan a conclusiones 
Rio de Janeiro. Ano 11. Volume 18. Número 3. Setembro a Dezembro de 2017

Periódico Quadrimestral da Pós-Graduação Stricto Sensu em Direito Processual da UERJ

Patrono: José Carlos Barbosa Moreira. ISSN 1982-7636. pp. 04-44

www.redp.uerj.br

distintas, no existe ningún otro criterio científicamente válido para decidir quién tiene la razón.

\section{CUALIDADES ESPECÍFICAS DE LA CIENCIA.}

Siguiendo los criterios desarrollados por el profesor Gustavo Cuello Iriarte ${ }^{10}$, la ciencia debe ser apreciada por el juzgador de la siguiente manera:

1. La objetividad: La ciencia debe apartarse, en la medida de lo posible de prejuicios, costumbres, tradiciones, meras impresiones u opiniones, etc.

2. La racionalidad: La ciencia se vale de la razón como herramienta para el logro de resultados. De esta manera se aparta de la religión y de todos los conocimientos no racionales.

3. La sistematicidad: La ciencia se preocupa por construir un sistema de ideas organizadas racionalmente.

4. La generalidad: A la ciencia le interesa llegar a una comprensión cada más extensa de las cosas.

5. La falibilidad: La ciencia debe aceptar su propia capacidad de equivocarse. Siendo consciente de sus limitaciones, la ciencia podrá autocorregirse y superarse.

6. Una teoría científica siempre puede ser refutada o sometida a cuestionamiento. Ser escéptico es esencial para la consolidación de la ciencia y su propia evolución.

7. La verificabilidad o comprobabilidad es necesaria, según el tipo de ciencia que se trate.

\section{VALORACIÓN DE LA PRUEBA CIENTÍFICA.}

El juez o árbitro no tiene por función sustituir al experto o perito, o pretender convertirse en un científico o técnico improvisado. Esto puede traer como consecuencia, que se asuma de manera pasiva o sumisa el dictamen pericial, trasladando casi literalmente

\footnotetext{
${ }^{10}$ CUELLO IRIARTE, Gustavo. Derecho Probatorio y Pruebas Penales, LEGIS, Bogotá, 2008, pp. 223 y
} 224. 
su contenido o conclusiones, para sustentar una decisión sobre determinados hechos invocados por las partes. La labor del juez o del árbitro debe ser distinta. Consiste en controlar el trabajo del experto para verificar la credibilidad y la validez del resultado que proporciona al proceso la prueba científica o técnica.

El juez o árbitro debe valorar la correcta realización del procedimiento y la validez del método, que ha sido seguido para la realización de la prueba científica o técnica. Como lo ha reiterado el profesor Taruffo, el juez debe operar como un epistemólogo, es decir, como un sujeto que verifica la validez del método con el cual han estado uniendo determinados resultados probatorios. Solo actuando de esta manera se neutraliza lo que se ha denominado el "efecto CSI", como la serie de televisión en la que la investigación forense prácticamente sustituye a los jueces.

En resumen, la fiabilidad de una prueba que pretende ser considerada como científica o técnica, depende de:
A) Validez científica del método usado.
B) Tecnología apropiada.
C) Rigurosos controles de calidad (correcta técnica del procedimiento).
D) Cualidades del experto o perito.

En el caso de los árbitros, considero que la exigencia en la correcta valoración de la prueba científica o técnica, debe ser más rigurosa o de un altísimo estándar. Por varias razones: i) es instancia única (la revisión judicial, vía anulación, no puede entrar directamente a la actividad de valoración probatoria que hicieron los árbitros- salvo una grosera y manifiesta arbitrariedad en tal actuación); ii) los árbitros han sido designados sobre la base de su especialidad, que a su vez, tiene relación con la materia controvertida; y iii) la confianza que las partes han depositado en lo árbitros también importa una alta dedicación para resolver el caso. 
Un tema a tener en consideración es el desarrollado por la profesora Carmen Vásquez Rojas ${ }^{11}$, con relación al backround del juez. Éste está compuesto por las creencias

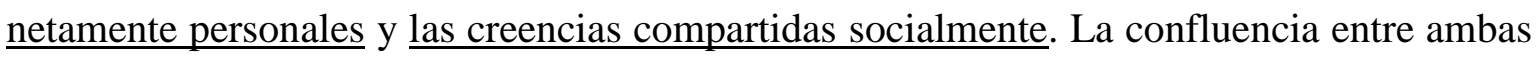
creencias es justamente lo que se busca, que incremente su backround, sobre todo en lo que se refiere a sus conocimientos científicos; lo cual, enriquecerá esa zona intermedia de las creencias del juez ${ }^{12}$.

La profesora Vasquéz ${ }^{13}$, pone de relevancia dos errores que comúnmente se cometen cuando se indica que el juez debe valorar los dictámenes periciales tomando en cuenta sus propias máximas de experiencia:

- Primer Error: no distinguir entre las creencias personales y las sociales.

- Segundo Error: se confunde el rol del backround del juez con los criterios de valoración y los estándares de la prueba. Las máximas de experiencia le sirven al juez para apreciar lo que se está diciendo, las pruebas que sus sentidos perciben, etc. En cambio, los criterios de valoración sirven para apreciar la calidad de la prueba; y los estándares de prueba son reglas de decisión sobre la suficiencia que produce en el juez el conjunto de pruebas. Es decir, luego de aplicar el principio de valoración individual de la prueba relevante, el juez hace un balance general que le permite llegar a un convencimiento sobre los hechos que se pretenden acreditar en el caso concreto. Esto último responde al principio de unidad de la prueba, porque debe quedar claro que la valoración conjunta viene después del estudio individualizado de cada medio probatorio o elemento probatorio calificado como relevante ${ }^{14}$.

\section{VII. ¿ES EL ADN LA PRUEBA PERFECTA?}

\footnotetext{
${ }^{11}$ VASQUEZ ROJAS, Carmen. De la prueba científica a la prueba pericial. Marcial Pons, Madrid, 2015, pp. 185,186 y 187.

${ }^{12}$ Los jueces deben recibir permanente capacitación en ámbitos extrajurídicos que resulten de utilidad para su trabajo. Por ejemplo, genética, economía, principios contables, sociología, etc.

${ }^{13}$ VASQUEZ ROJAS, Carmen. Ob. Cit. p. 186.

14 PARRA QUIJANO, Jairo. Manual de Derecho Probatorio. Librería Ediciones del Profesional LTDA. Colombia, 2004, p.7.
} 
1. Como lo indica la bióloga Maria Isabel Quiroga ${ }^{15}$, la prueba de ADN se sustenta en las diferencias genéticas entre los seres humanos. Esto hace que las características del ADN de una persona sean únicas e inmutables y están determinadas desde el momento mismo de la concepción, por la dotación genética que se recibe de los padres, y a través de ellos, de los ancestros. Está dotación genética se denomina genoma, que es propio de cada individuo e idéntico en cada una de las billones de células que forman un organismo.

2. Por eso se puede afirmar que no existen dos personas con igual ADN, salvo el caso de los gemelos idénticos.

3. El ADN es transmitido de padres a hijos, de los cromosomas del óvulo y del espermatozoide. Cada padre transmite al concebido la mitad de su ADN. Por eso, nuestro ADN proviene de los padres y la comparación que se haga del ADN de dos personas permite determinar si hay algún vínculo genético entre ambas.

4. Para el caso de las pruebas de paternidad, se usa técnicas de genética molecular y puede extraerse de cualquier célula del organismo. Lo más común es obtener células de la sangre o de la mucosa oral (interior de los labios y mejillas). Para tal efecto, se toma una muestra de cada una de las tres personas involucradas (el hijo, la madre y el posible padre). Se buscan en el presunto padre aquellas marcas o alelos (formas alternativas de un gen que se hayan en el mismo locus ${ }^{16}$ de los cromosomas homólogos. Los alelos se segregan durante la meiosis ${ }^{17}$ y el hijo solo recibe uno de cada par de alelos de cada progenitor), que estando presentes en el hijo no se encuentran en la madre. La falta de coincidencia de dos de estas marcas es suficiente para excluir la paternidad con $100 \%$ de seguridad.

${ }^{15}$ QUIROGA DE MICHELENA, María Isabel. LA PRUEBA DE ADN. Fundamentos biológicos de la determinación de paternidad y otras aplicaciones médico legales. En: La Prueba de ADN, Cuadernos Jurisprudenciales, Año 4, Número 37, Gaceta Jurídica, Lima, 2004, pp. 19, 20 y 21.

${ }^{16}$ Locus: Localización exacta de un gen o un segmento de ADN en un cromosoma. Las diferentes formas del gen (alelos) ocupan siempre la misma posición en el cromosoma. Plural: loci.

${ }^{17}$ Meiosis: Tipo especial de división celular que ocurre en las gónadas, en el cual a partir de células diploides se forman los gametos (cada una de las células germinativas: óvulo o espermatozoide). 
5. De otro lado, si el presunto padre tiene todos los alelos que el niño posee y que no ha heredado de su madre, entonces su paternidad queda demostrada. Para este efecto, es muy importante señalar que el análisis de un solo locus no es determinante de paternidad, debe examinarse un número variable, generalmente entre 5 y 15 loci, para llegar a excluir la paternidad o alcanzar una probabilidad mayor de 99.9\%. Es decir, el tamaño del fragmento de ADN que se mide en kb (miles de bases), es esencial para lograr el alto grado de certeza que busca esta prueba biológica.

6. También es importante resaltar que, el perfil de ADN es muy usado en la medicina forense, con el propósito de establecer la procedencia de algún resto biológico (sangre, semen, pelo). Por ejemplo, para comparar el ADN de un presunto violador con el de la sangre de varios sospechosos: el perfil de ADN del criminal será idéntico al encontrado en el semen, de igual modo puede compararse la raíz del pelo, sangre, piel dentro de las uñas de la víctima, con muestras biológicas de sospechosos.

7. Llevada de manera correcta, debido al elevado porcentaje de certeza, esta evidencia biológica puede ser calificada como la prueba perfecta, y debería producir plena certeza al momento de juzgar.

8. Sin embargo, la validez del test genético depende de una serie de condiciones relativas a la cualidad (tamaño de los alelos), a la recolección y conservación de los materiales genéticos, desde el uso del procedimiento correcto, hasta la seriedad del laboratorio y el experto que lo realizó.

9. El problema de muchos países, como es el caso del Perú, es que no tienen una Carta o Guía Genética, o regulaciones mínimas para la correcta realización de una prueba de ADN.

10. La idoneidad de los laboratorios es todo un problema porque debería existir una previa certificación y habilitación para su correcto funcionamiento, sean públicos o 
privados. Para ello también, resulta imprescindible exigir a los laboratorios certificaciones de calidad que se rigen por normas ISO.

11. La habilitación debe estar a cargo del Estado o de una entidad científica autorizada para tal labor. Es muy importante asegurar que el laboratorio donde se practicarán las pruebas, cumpla con las normas sanitarias que la regulación provea.

12. La prueba de ADN puede presentar los siguientes problemas, que eventualmente afectarían su alta probabilidad de certeza:

12.1. Cuando los laboratorios no cuentan con los expertos adecuados (inmunogenetistas, hematólogos, bioquímicos especializados en enzimas, biólogos moleculares, especialistas en bioestadísticas, etc.).

12.2. Cuando el laboratorio no disponga de un adecuado sistema de computación, como es el caso de los analizadores genéticos automáticos.

12.3. También la falibilidad de estos exámenes de última generación, puede obedecer al insuficiente tamaño del grupo o cantidad de los alelos.

12.4. La ausencia de condiciones apropiadas de asepsia o higiene durante el procedimiento de manipulación de las muestras.

12.5. El hecho de que el ADN se encuentre degradado o afectado por la contaminación proveniente de bacterias, o que haya acontecido la denominada "contaminación cruzada".

12.6. Riesgo de resultados equívocos si durante el análisis no se ha mantenido la temperatura adecuada (exposición a ambiente caluroso o húmedo).

Este listado preparado por el profesor argentino Marcelo Sebastián Midón ${ }^{18}$, constituye una guía útil para que el juez o árbitro actúe como un verdadero epistemólogo, sometiendo a la prueba de ADN a un control de fiabilidad en la obtención y concreción del medio probatorio.

\footnotetext{
${ }^{18}$ MIDÓN, Marcelo Sebastián. Pericias Biológicas, Ediciones Jurídicas Cuyo, Mendoza - Argentina, 2005, pp. 163, 164, 165, 170 y 171.
} 


\section{LA NEUROCIENCIA Y EL PROCESO.}

Como bien lo ha advertido el profesor René Molina ${ }^{19}$, las investigaciones realizadas por la neurociencia evidencian que el Derecho va a ser afectado de manera irremediable.

El tema es si realmente somos conscientes del impacto y si estamos preparados para enfrentarlo. La primera respuesta que se me viene a la mente es negativa. Veamos algunos ejemplos de afectación al derecho por parte de la neurociencia:

1. La neurociencia como herramienta para un sistema de selección de jueces: Los científicos han desarrollado herramientas que pueden utilizarse para comprobar que la teoría del pensamiento basado en la justicia, tiene lugar de manera independiente del razonamiento sustentado en reglas. Cuando se piensa en la justicia, se refleja en un algoritmo no verbal, soportado por una mezcla de huellas genéticas, herencia cultural y experiencia. Con estos avances científicos será posible preparar un determinado perfil para quien aspire a ejercer el cargo de juez; sometiendo al candidato a un examen neurocientífico para determinar si está realmente preparado para ejercer tan importante función pública.

2. La neurociencia: la libertad, responsabilidad e imputabilidad: ¿Cuán responsables somos de nuestras acciones? ¿Cómo influye la edad en la responsabilidad?

Para ello hay que tener en cuenta que las investigaciones demuestran que, durante la adolescencia se registran procesos de maduración biológica del cerebro (entre los 16 a 17 años). Es por ello que, los resultados ofrecidos por la neurociencia, han demostrado que los jóvenes tienen una menor capacidad que los adultos para inhibir sus comportamientos y controlar sus impulsos.

\footnotetext{
${ }^{19}$ MOLINA GALICIA, René. Neurociencia, Neuroética, Derecho y Proceso. En: Neurociencia y proceso judicial, Directores: TARUFFO, Michele y NIEVA FENOLL, Jordi, Marcial Pons, Madrid, 2013, pp. 47, 48, 49,52 y 62 .
} 
Tan relevante está siendo la neurociencia que, en el caso Roper vs Simmons (2005), la Corte Suprema de EEUU, apoyada en estudios neurocientíficos, abolió la pena de muerte para los jóvenes con una edad inferior a los 18 años.

\section{LA NECESIDAD URGENTE DE REPLANTEAR LA ENSEÑANZA}

\section{DEL DERECHO.}

1. Si bien es cierto, la enseñanza del derecho en el Perú está en permanente crisis, considero importante advertir que no podemos vivir al margen de la sociedad del conocimiento y de la influencia de la ciencia en el proceso.

2. Por eso, es imprescindible que las facultades de derecho incorporen como materia de estudio los avances de la ciencia; como la psicología, biología y neurociencia (todo lo que tenga que ver con el comportamiento humano). La ciencia y el derecho ya no pueden andar por separado.

3. Los jueces o árbitros también tienen el deber de conocer los avances de la ciencia y tecnología, e incorporarlos a sus conocimientos generales o máximas de experiencia. Nuestra sociedad, cada vez más tecnificada, traslada sus problemas al sistema judicial o arbitral, aportando al proceso pruebas de diversa índole científica y/o técnica. Y si los jueces o árbitros no están preparados siquiera para valorar prueba compleja, es muy probable que los expertos o peritos sean quienes definan el resultado del caso, sin ningún tipo de control respecto de la fiabilidad o grado de certeza de la prueba aportada.

\section{LA PRUEBA CIENTÍFICA EN LOS PROCESOS}

\section{CONSTITUCIONALES: EL AMPARO.}

1. Teniendo en consideración la naturaleza del Amparo como proceso de tutela de urgencia para la protección de los derechos fundamentales y sociales complementarios a la libertad, reconocidos por la Constitución y los tratados internacionales; la prueba como 
herramienta esencial para la acreditación de los hechos lesivos a tales derechos, debe, también, estar acorde con la estructura y función de este tipo de proceso constitucional.

2. Como lo indica María Mercedes Serra, el proceso de amparo se diferencia del ordinario por la finalidad que persigue y la materia tratada, y porque además constituye un instrumento procesal diseñado para garantizar la supremacía constitucional y proteger de manera simple, rápida y directa los derechos fundamentales ${ }^{20}$.

3. En ese orden de ideas, es de suponerse que la prueba tiene una especial importancia por los derechos que se someten al conocimiento del juez constitucional, y por la necesidad de que la tutela buscada acabe lo más pronto posible. Esto implica una limitación respecto a la prueba que se pueda aportar y a la inmediatez en su apreciación o actuación. Veamos.

4. Morello y Vallefín ${ }^{21}$, al comentar el artículo 2 inciso d) de la Ley $16986^{22}$ (Ley de Amparo argentina), precisaron que la vía del amparo no resulta procedente para cuestiones que requieran mayor amplitud de debate o de prueba. Sin embargo, también advierten que los jueces deben extremar su ponderación y prudencia, a fin de no decidir por el proceso de amparo cuestiones susceptibles de mayor debate y que correspondería resolver ante la justicia ordinaria.

5. En una línea más avanzada, el profesor Néstor Pedro Sagües ${ }^{23}$, pide no hacer una exégesis liviana de la norma antes referida. La complejidad fáctica no es suficiente para rechazar el amparo, el profesor argentino advierte que no debe descartarse $a$ priori la demanda, sino solo en aquellos casos en los que se requiera un aporte de pruebas superior al que normalmente puede ofrecerse en un proceso breve como el amparo.

\footnotetext{
${ }^{20}$ SERRA, María Mercedes. A propósito del rechazo in limine en el amparo. En: El Amparo Constitucional, Directores: BIDART CAMPOS, Germán y SAGÜES, Néstor, Depalma, Argentina, 1999, p. 91.

${ }^{21}$ MORELLO, Augusto y VALLEFÍn, Carlos. El Amparo. Régimen Procesal. Librería Editora Platense, La Plata, 1998, pp. 38 y 39.

22 "...si la determinación de la eventual invalidez del acto requiriese una mayor amplitud de debate o de prueba...".

${ }^{23}$ SAGÜES, Néstor Pedro. Compendio de derecho procesal constitucional. ASTREA, Buenos Aires, 2009, pp. 474 y 475 .
} 
6. Ahora, en mi opinión, quien aboga por una flexibilización a la limitación probatoria en el proceso de amparo, es el profesor Osvaldo Gozaíni. Y, me parece, hasta ahora, la posición más acorde con las reales necesidades de justicia constitucional. Veamos por qué.

7. Pese a que el amparo es un proceso de estructura concentrada con una evidente limitación probatoria, el profesor Gozaíni ${ }^{24}$ invita a reconducir el objeto de la prueba en los procesos constitucionales y no usar como excusa el problema de la dificultad probatoria para el rechazo del amparo.

8. Es importante resaltar la siguiente idea del profesor argentino: "La principal tarea del juez en el amparo es la concentración de los actos de prueba. Al no perder ninguna de las facultades procesales que cuenta en los juicios de conocimiento, ellas pueden ser actuadas. El restriccionismo anterior respecto a la necesidad de mayor debate y prueba como pauta de rechazo para tramitar el proceso constitucional no puede surtir de excusa para efectuar el control de constitucionalidad. De hacerlo, el único beneficiado es el presunto infractor, que obtiene de un ritualismo la convalidación de sus actos $u$ omisiones que se derivan a un proceso ordinario para elaborar en su irreal eficacia la prueba necesaria, 25 .

9. Si puedo resumir en una expresión el pensamiento del profesor Gozaíni, podría decir que el juez constitucional debe buscar un adecuado balance entre el derecho a la prueba y el debido proceso; para que el amparo no sea desnaturalizado, pero que tampoco el excesivo celo o ritualismo sea un obstáculo para acceder a una técnica procesal adecuada o idónea que permita una tutela efectiva y específica a los derechos materiales. Ya lo dijo el profesor Marinoni; “...el derecho de acción...además de adquirir la función de derecho de acceso a la justicia, asume la figura de derecho a la preordenación de

\footnotetext{
${ }^{24}$ GOZAÍNI, Osvaldo. Tratado de Derecho Procesal Constitucional, tomo I, Editorial Porrua, México, 2011, pp. 741 y 742 .

${ }^{25}$ GOZAÍNI, Osvaldo. Ob. Cit, p. 744.
} 
técnicas procesales idóneas a la viabilidad de la obtención de las tutelas prometidas por el derecho sustancial, 26

10. Si queremos que el amparo siga siendo una técnica idónea para la obtención de las tutelas prometidas o protegidas por la Constitución y los tratados internacionales en materia de derechos humanos, no recurramos al exceso de ritual manifiesto o a la fácil forma del rechazo in limine de la demanda de amparo. El Juez constitucional no debe olvidar que cumple un rol protagónico, es el que más cerca debe estar de nuestra realidad social, siempre atento para reprimir a la arbitrariedad, ejerciendo de manera permanente el control de la constitucionalidad y el de convencionalidad. Observando siempre, para tal efecto, los tratados internacionales en la materia como la Convención Americana sobre Derechos Humanos (Pacto de San José de Costa Rica) y el Pacto Internacional de Derechos Civiles y Políticos de Naciones Unidas.

11. Es por ello, que el profesor español Aragón Reyes, citado por Gozaíni, indica lo siguiente: "para interpretar y aplicar los derechos no sirve la scientia iuris, sino que precisa la iuris prudentia, capaz de incorporar la realidad a la norma a través del caso y de utilizar la equidad para buscar la solución normativa a través del principio de proporcionalidad $^{, 27}$. Ese debe ser el rol del juez constitucional, liberarse del yugo de la ley para trascender con sus decisiones en nuestra sociedad.

12. En sede nacional, Felipe León Florían, indica que las causales de improcedencia de la demanda de amparo no solo deben ser apreciadas a partir del listado contenido en el artículo 5 del Código Procesal Constitucional. El artículo 9 del referido Código $^{28}$, también puede ser usado como una limitación para el acceso al amparo. Es decir, si la controversia resulta compleja, en lo concerniente a la determinación de los hechos, el amparo no sería el proceso adecuado, por carecer de estación probatoria. Pero, al mismo

\footnotetext{
${ }^{26}$ MARINONI, Luis Guilherne. El Derecho Fundamental de acción en la Constitución brasileña. En: Boletín Mexicano de derecho comparado No.123, UNAM, México, 2008, p. 1383.

${ }^{27}$ GOZAÍNI, Osvaldo, Ob. Cit. p. 91.

${ }^{28}$ Artículo 9.- Ausencia de etapa probatoria.

En los procesos constitucionales no existe etapa probatoria. Sólo son procedentes los medios probatorios que no requieren actuación, lo que no impide la realización de actuaciones probatorias que el juez considere indispensables, sin afectar la duración del proceso. En este último caso no se requerirá notificación previa.
} 
tiempo advierte, como mucho tino, que el hecho que un caso sea complejo no es causa suficiente para determinar la improcedencia de la demanda de amparo, debido a una eventual dificultad probatoria. “...no quiere decir strictu sensu que la complejidad y la necesidad de actuación probatoria hagan de por sí improcedente el amparo, sino solo significa que, de lo aportado por el demandante, en el caso concreto, no se observa con claridad (ni siquiera con proximidad) los elementos que configuran el acto lesivo, ni se muestran elementos que puedan llevar al juez a una actuación probatoria de oficio",29, apunta acertadamente el citado autor.

13. Teniendo en consideración lo anteriormente desarrollado, es perfectamente posible que en el proceso constitucional, como lo es el amparo, se debatan temas que tengan relación directa o indirecta con la ciencia o la técnica. Ello, porque la evidencia científica no solo puede estar reflejada a través de una pericia, medio probatorio que necesariamente debe tener una etapa de actuación probatoria. No olvidemos que la ciencia puede estar presente en muchas actividades humanas $\mathrm{y}$, por ende, determinadas acciones $\mathrm{u}$ omisiones pueden afectar derechos constitucionales; como sería el caso de medicinas defectuosas o riesgosas para la salud, o cuestionamientos a métodos artificiales de fecundación.

La prueba científica o técnica también puede ser incorporada al proceso constitucional mediante prueba documental. Por ejemplo, aportando publicaciones científicas que reflejen la opinión de expertos sobre el tema que es objeto de discusión. Ello lo veremos más adelante cuando haga referencia al caso de "la píldora del día siguiente" o al derecho de los transexuales de cambiar el sexo en su documento de identidad. No hay que olvidar que el juez constitucional puede hacer un amplio uso de sus poderes probatorios, y hacer uso de la potestad de convocar a las partes a una audiencia para que presenten sus posiciones y expliquen la ciencia o técnica que la sustenta; por ejemplo, el efecto abortivo o no de la píldora anticonceptiva. Inclusive, el juez puede

\footnotetext{
${ }^{29}$ LEÓN FLORÍAN, Felipe Johan. Sobre la prueba en el proceso de amparo. En: La prueba en el proceso constitucional. Dialogo con la Jurisprudencia, Guía Práctica 4, Lima, 2010, p.74.
} 
convocar a expertos para que ilustren o expliquen, desde su ciencia o conocimiento, los alcances de determinada materia que puede resultar compleja.

Es claro que los debates científicos han llegado al proceso, no podemos ponernos una venda y remitir de manera automática al proceso ordinario cualquier controversia compleja que implique recurrir a la ciencia o la técnica. Cuando a veces solo es necesario comprobar una verdad científica para descartar una conducta contraria a nuestro ordenamiento constitucional.

Veamos un ejemplo en el caso del derecho constitucional a la educación y que esta no se vea afectada por la imposición de dogmas religiosos. Peré Estupinyá ${ }^{30}$, comenta que parece absurdo tener que defender a estas alturas la teoría de la evolución de Darwin. Pero, en Estados Unidos, una encuesta publicada en la revista Nature en 2007 demostró que la mitad de la población adulta no acepta la tesis de Darwin; en pleno siglo XXI!! Y esta realidad no tardó en llegar a las cortes norteamericanas. Los fundamentalistas religiosos en más de una oportunidad han intentado interferir en el derecho a la educación científica que tienen los alumnos, disfrazando de científicas sus creencias, para poder introducirlas en los programas curriculares de las escuelas públicas. Primero lo intentaron con el denominado “creacionismo científico", luego en la década de 1980, un juez felizmente dictaminó que resultaba obvio que el mensaje no era científico sino religioso. En el 2005 los fundamentalistas religiosos volvieron al ataque, e inventaron el concepto de "diseño inteligente" para "explicar" en las escuelas el origen de las especies. Tuvo que intervenir un juez para darle la razón nuevamente a la biología; el denominado "diseño inteligente" no era parte de la ciencia, sino una ideología religiosa.

\section{LA PRUEBA CIENTÍFICA EN EL PROCESO PENAL.}

\footnotetext{
${ }^{30}$ ESTUPINYÁ, Peré. Ob. Cit. p.213.
} 
1. Es de resaltar que nuestra justicia penal ha dado un paso muy importante en fijar un criterio jurisprudencial en materia de prueba científica. Me refiero al IX Pleno Jurisdiccional de los Jueces Supremos en lo Penal de fecha 02 de octubre de $2015^{31}$.

2. Los jueces supremos han asimilado correctamente los siguientes criterios para la valoración de las pruebas científicas:

2.1. Se adoptaron criterios para la evaluación de la validez y fiabilidad de la prueba pericial.

2.2. De ello se deriva la diferenciación entre lo que puede considerarse ciencia de la que no lo es. Para lograr tal propósito nuestra Corte Suprema, siguiendo a la jurisprudencia norteamericana, ha propuesto lo siguiente:

a) La controlabilidad y falsabilidad de la teoría científica, o la técnica en que se fundamenta la prueba, lo que implica que la teoría haya sido probada de forma empírica, no solo dentro de un laboratorio.

b) El porcentaje de error conocido o potencial, así como el cumplimiento de los estándares correspondientes a la prueba empleada.

c) La publicación en revistas sometidas al control de otros expertos de la teoría o técnica en cuestión, lo que permite su control y revisión por otros expertos.

d) La existencia de un consenso general de la comunidad científica interesada.

3. Agregan nuestros jueces supremos en lo penal, que el criterio de la aceptación general (general acceptance) deja de ser el único elemento de decisión (como se había establecido en el caso Frye). Ahora, la decisión sobre la admisión de este medio de prueba ya no corresponde únicamente a la comunidad científica sino al juez, quien deberá controlar la confiabilidad de la prueba científica, con arreglo a dichos criterios, y exponer

\footnotetext{
${ }^{31}$ Acuerdo Plenario No.4-2015/CIJ-116, publicado en el diario Oficial El Peruano el 21 de junio de 2016.
} 
los motivos de su inadmisión. Y en caso que la conclusión no se desprenda de los datos que señala en su dictamen, el Tribunal tiene la libertad de determinar que existe un análisis inaceptable entre las premisas y la conclusión.

4. Considero que esta jurisprudencia, dado su alcance, por las reglas y principios generales que ha desarrollado en materia de prueba científica, vincula a todas las especialidades de nuestro sistema de justicia, conforme lo establece el artículo 22 de la Ley Orgánica del Poder Judicial ${ }^{32}$.

5. Las citadas reglas jurisprudenciales, fueron aplicadas a un caso concreto. Se trata del llamado caso Oyarce (Sala Penal Transitoria R.N.N. 1658-2014- LIMA, de fecha 15 de marzo de 2016). Este es un caso de violencia en el ámbito del fútbol nacional, en el que un joven barrista perdió trágicamente la vida cuando fue atacado en un estadio por otros barristas del equipo contrario, lanzándolo desde una altura superior a los 9 metros. En el proceso penal se actuaron diversas pericias de orden técnico y científico; unas para intentar acreditar la tesis del "auto impulso" y las otras para acreditar, como finalmente ocurrió, el uso de una "fuerza externa" que ocasionó la caída del joven barrista. Para lograr tal tarea, los señores jueces supremos en lo penal, recurrieron a la jurisprudencia comparada del caso "Daubert vs Merrell Down Pharmaceuticals". Por ende, las pericias aportadas fueron analizadas bajo los siguientes criterios:

a) Que la conclusión científica tenga fundamento fáctico.

\footnotetext{
${ }^{32}$ Artículo 22.- Las Salas Especializadas de la Corte Suprema de Justicia de la República ordenan la publicación trimestral en el Diario Oficial "El Peruano" de las Ejecutorias que fijan principios jurisprudenciales que han de ser de obligatorio cumplimiento, en todas las instancias judiciales.

Estos principios deben ser invocados por los Magistrados de todas las instancias judiciales, cualquiera que sea su especialidad, como precedente de obligatorio cumplimiento. En caso que por excepción decidan apartarse de dicho criterio, están obligados a motivar adecuadamente su resolución dejando constancia del precedente obligatorio que desestiman y de los fundamentos que invocan.

Los fallos de la Corte Suprema de Justicia de la República pueden excepcionalmente apartarse en sus resoluciones jurisdiccionales, de su propio criterio jurisprudencial, motivando debidamente su resolución, lo que debe hacer conocer mediante nuevas publicaciones, también en el Diario Oficial "El Peruano", en cuyo caso debe hacer mención expresa del precedente que deja de ser obligatorio por el nuevo y de los fundamentos que invocan.
} 
Rio de Janeiro. Ano 11. Volume 18. Número 3. Setembro a Dezembro de 2017

Periódico Quadrimestral da Pós-Graduação Stricto Sensu em Direito Processual da UERJ Patrono: José Carlos Barbosa Moreira. ISSN 1982-7636. pp. 04-44 www.redp.uerj.br

b) Que se hayan integrado principios y metodologías fiables.

c) Que la conclusión sea aplicable a lo sucedido de manera verificablemente correcta.

Estos criterios, entre otros, llevaron a la Sala Penal de la Corte Suprema a condenar a los agresores a una pena de 25 años de cárcel. Este ha sido caso emblemático, no solo por la atención que suscitó en el público por los actos de violencia que se producen en el fútbol, sino porque además, los jueces recurrieron a la ciencia para sustentar una condena.

XII. LA PRUEBA CIENTÍFICA EN LOS TRIBUNALES INTERNACIONALES: LA CORTE INTERAMERICANA DE DERECHOS HUMANOS (CIDH).

EL CASO ARTAVIA MURILLO vs COSTA RICA. FECUNDACIÓN IN VITRO (FIV), 28 DE NOVIEMBRE DE 2012.

1. Se demandó al Estado de Costa Rica a causa de una sentencia expedida por la Sala Constitucional de ese país, que declaró inconstitucional un determinado tipo de Fecundación In Vitro (FIV).

2. La Corte Constitucional de Costa Rica argumentó que la FIV, afectaba a la vida de los embriones que eran descartados, argumentando lo siguiente: "La vida humana se inicia desde el momento de la fecundación, por lo tanto, cualquier eliminación o destrucción de concebidos voluntaria o derivada de la impericia del médico o de la inexactitud de la técnica utilizada, resultaría en una evidente violación del derecho a la vida contenido en la Constitución costarricense”.

\section{¿QUÉ DIJO LA CIDH?}

3. La Corte sustentó su decisión en dictámenes periciales científicos y en literatura de la ciencia médica. 
4. Se llegó de determinar que Costa Rica fue el único Estado que prohibió de manera expresa la FIV.

5. La Corte reconoció que no hay consenso científico respecto a cuándo comienza la vida, o desde cuándo es sujeto de protección el embrión.

6. La Corte actuó y valoró prueba científica contenida en pericias y doctrina médica sobre el tema en cuestión. Para tal efecto, describió las tres teorías sobre la concepción:

6.1. "Concepción I": desde el momento en que el óvulo es fecundado por el espermatozoide. De la fecundación se crea una nueva cédula: el cigoto.

6.2. “Concepción II": como el momento de implantación del óvulo fecundado en el útero. El cigoto se conecta con el sistema circulatorio materno.

6.3. Y la tercera teoría, pero menos aceptada, indica que la vida comienza cuando recién se desarrolla el sistema nervioso.

Lo descrito evidencia que no hay consenso científico, respecto desde qué momento se produce la concepción.

7. Pese a la falta de consenso científico, la CIDH asumió una posición e indicó que la "concepción" comienza cuando el embrión se implanta en el útero (fecundación + implantación). Teniendo en cuenta la posición científica asumida, la Corte desarrolló las siguientes consecuencias jurídicas respecto del embrión y de la madre:

7.1. Recién a partir de la implantación se aplica el artículo $4^{\circ}$ de la Convención (derecho a la vida).

7.2. No obstante ello, el objeto de protección es la mujer embarazada, y concluye que no es procedente otorgar el estatus de persona al embrión.

7.3. La expresión "ser humano" utilizada en la Declaración Universal de los Derechos Humanos, no ha sido entendida en el sentido de incluir al no nacido. 
7.4. Según la Corte, el embrión no puede ser tratado como persona. El embrión puede ser protegido en nombre de la dignidad humana, sin convertirlo en "persona" con derecho a la vida.

7.5. La protección del derecho a la vida con arreglo al artículo $4^{\circ}$ de la Convención no es absoluta, sino es gradual e incremental según su desarrollo.

7.6. El derecho absoluto a la vida del embrión como base para la restricción de los derechos involucrados, no tiene sustento en la Convención Americana sobre Derechos Humanos.

Como se puede apreciar de esta apretada síntesis, la posición asumida por la CIDH, usando como sustento determinada evidencia científica, tiene consecuencias en todo el sistema interamericano, afectará directamente las legislaciones estatales y las decisiones judiciales que de ahora en adelante vayan a emitir los jueces que forman parte del sistema.

No es este el espacio para realizar una crítica profunda a la decisión asumida por la CIDH; sin embargo, no puedo dejar de advertir que el embrión dejó de ser sujeto de protección directa, otorgando a la madre embarazada poder de decisión sobre su condición. Las consecuencias sobre el aborto son graves.

Demás está decir, que la CIDH ni por asomo usó las técnicas aportadas por el precedente DAUBERT y que han sido recogidas por la doctrina continental de manera pacífica.

XIII. LA PRUEBA CIENTÍFICA ANTE EL TRIBUNAL CONSTITUCIONAL PERUANO.

CASO No. 00139-2013-PA/TC, DE FECHA 18 DE MARZO DE 2014. SAN MARTIN P.E.M.M. REPRESENADO(A) POR RAFAEL INGA ZEVALLOS. TRANSEXUALIDAD Y CIENCIA. VERSIÓN I.

1. El demandante interpuso una demanda de amparo contra el RENIEC (organismo estatal a cargo del registro e identificación de las personas), solicitando el cambio de sexo (de masculino a femenino), en su documento nacional de identidad -DNI. De igual modo, que se produzca dicho cambio en su partida de nacimiento. 
2. El demandante se calificó como "transexual" o "mujer reasignada", mediante una cirugía de cambio de sexo.

3. La sentencia emitida por la mayoría de los miembros del Tribunal Constitucional declaró infundada la demanda de amparo.

4. Gran parte del sustento de dicha decisión se basó en un análisis de naturaleza científica. El debate se centró entre el "sexo biológico" y el "sexo psíquico"; y cuál de ellos debía prevalecer.

5. Según el Tribunal Constitucional el único sexo a tener en consideración es el "sexo biológico". Para llegar a tal conclusión, recurrió a determinada ciencia que indica que el sexo biológico o cromosómico no se puede cambiar o alterar.

6. Como consecuencia de ello, según el Tribunal Constitucional surge la "doctrina de la indisponibilidad del sexo".

7. El Tribunal Constitucional indicó que solo se puede rectificar el registro por algún "error en la transcripción". Además, justificó como único supuesto de desajuste en el propio sexo cromosómico, en los casos de intersexualidad o hermafroditismo (error en la apreciación del sexo).

8. El caso del transexualismo, lo calificó como una patología de orden psicológico (enfermedad mental).

9. El Tribunal Constitucional también advierte que la cirugía para el trastorno de la transexualidad y consecuente prevalencia del sexo psíquico sobre el cromosómico, está sujeto a una gran polémica en el mundo científico. Agregó, que la cirugía no es aceptada pacíficamente en el campo científico, que también hay tratamientos psicológico- 
psiquiátricos, para que el "paciente" acepte su sexo biológico y, sobre la base de ello, construya su identidad.

10. Siguiendo esa línea, el Tribunal Constitucional realiza la siguiente conclusión científica: "El cambio de sexo no es posible, incluso con la cirugía más perfecta".

11. También estableció que el criterio científico mayoritario es el de la prevalencia del sexo biológico, por encima de lo que defiende el criterio minoritario respecto del sexo psíquico. Y, sobre la base de tal aseveración, indicó que el derecho deberá interpretar sus normas o cambiar su legislación a la luz de lo que aporte la ciencia médica al respecto.

12. Para reforzar lo indicado en el numeral precedente, se argumentó que existen escuelas científicas que abogan por el tratamiento psicológico-psiquiátrico que procure curar al transexual, para que finalmente acepte su sexo biológico.

13. Además, Tribunal Constitucional se restringe y no dicta precedentes sobre temas polémicos que puedan dividir a la opinión pública; que ello es propio de los "jueces activistas" (afectación al principio de separación de poderes).

14. No obstante, los votos en minoría, en mi opinión, reflejan una posición científica mucho más sólida que, sin recurrir a la regla DAUBERT en materia de evaluación de la evidencia científica, se aproxima mucho. Veamos:

14.1. Se cuestionó severamente la existencia de las escuelas científicas que abogan por el tratamiento psicológico-psiquiátrico del transexual. Si se hubiese seguido la regla DAUBERT, la pregunta que hubiese sido formulada sería la siguiente: ¿Ha sido la teoría del tratamiento psicológico-psiquiátrico revisada por otros científicos? ¿Obedece a algún consenso científico? 
14.2. La comunidad científica ha rechazado las denominadas terapias reparativas, que supuestamente permitirían adaptar la identidad o el deseo sexual al sexo biológico.

14.3. Se cuestionó la total ausencia de respaldo científico a la decisión adoptada en mayoría. De haberse recurrido a las técnicas sugeridas por la regla DAUBERT, era altamente probable llegar a una distinción entre "ciencia buena" (good science) y "ciencia mala" (junk science).

14.4. Finalmente, contrario a lo que la ciencia, la doctrina y jurisprudencia comparada indican, la decisión adoptada en mayoría desconoce la categoría de "identidad de género".

Como es de verse, para esta polémica decisión, el transexual es considerado como un "enfermo mental".

CASO No. 06040-20135-PA/TC, DE FECHA 21 DE OCTUBRE DE 2016. $\begin{array}{llllll}\text { RODOLFO } & \text { ENRIQUE } & \text { ROMERO } & \text { SALDARRIAGA } & \text { (ANA } & \text { ROMERO }\end{array}$ SALDARRIAGA). TRANSEXUALIDAD Y CIENCIA. VERSIÓN II.

1. Apenas pasaron dos años, para que llegara otro caso de transexualidad con pretensiones de cambio de nombre y de sexo en los documentos de identidad (partida de nacimiento y DNI). Pero, ahora, estamos frente a un Tribunal Constitucional con nuevos integrantes.

2. El renovado Tribunal Constitucional, decidió dejar sin efecto la doctrina jurisprudencial que fuera establecida en la Sentencia No.0139-2013-PA/TC. Veamos de manera resumida qué llevó al Tribunal Constitucional a este cambio de criterio en materia de transexualismo.

3. En el Fundamento 6, se indicó que la anterior postura suponía un severo e irrazonable impedimento para la viabilidad de esta clase de pedidos ante el Poder Judicial. Por dos razones esenciales: i) no puede entenderse el transexualismo como una patología o enfermedad; y ii) existe la posibilidad de que, en ciertos casos, el derecho a la identidad personal faculte a un juez a reconocer el cambio de sexo. 
4. En el Fundamento 7, se menciona que en la anterior decisión se asumió que el transexualismo era una mera cuestión patológica y/o médica. Para refutar tal conclusión, en la nueva decisión el Tribunal Constitucional recurrió a la ciencia más actual para sustentar el cambio de criterio jurisprudencial. Citó a la American Psychological Association (APA), para afirmar que el enfoque de la enfermedad mental estaba superado. De igual modo, se explicó que la Organización Mundial de la Salud, estaba rumbo a superar la tipología de la enfermedad mental o trastorno de la personalidad, en los casos de transexualismo.

5. Concluye el Tribunal Constitucional, en su Fundamento 9, que el transexualismo debe ser entendido como una disforia de género, más no como una patología; así las cosas, y en consonancia con estas evidencias, respaldadas por la jurisdicción supranacional y los criterios asumidos por los organismos internacionales, corresponde dejar sin efecto este extremo de la doctrina jurisprudencial fijada en la STC 0139-2013-PA.

6. De esta manera el Tribunal Constitucional en sus fundamentos 13 y 14, aseveró que la realidad biológica no debe ser el único elemento determinante para la asignación del sexo. Reconociendo que existe un derecho a la identidad de género, el cual forma parte del contenido constitucionalmente protegido del derecho a la identidad personal.

De las dos sentencias materia de comentario, se pueden extraer las siguientes conclusiones: i) es claro que la prueba científica si puede ser objeto de análisis y de valoración en los procesos constitucionales; y ii) es altamente recomendable que los jueces constitucionales recurran a las reglas desarrolladas por los casos Daubert-Joiner-Kumho, para verificar la confiabilidad y validez de la información o datos científicos que se pretendan utilizar como elementos de convicción para la decisión a tomar en un caso concreto. 
CASOS No7435-2006-PC/TC DE FECHA 13 DE NOVIEMBRE DE 2006 Y No. 02005-2009-PA/TC DE FECHA 16 DE OCTUBRE DE 2009. AMBOS REFERIDOS AL TEMA DE LA “PILDORA DEL DIA SIGUIENTE”. DOS VERSIONES SOBRE UN MISMO TEMA.

1. En ambos casos se discute si la "anticoncepción oral de emergencia" o también llamada "píldora del día siguiente" tiene efectos en el embarazo ya iniciado y, si esta es abortiva o no. Y, si el Estado debe incorporarla dentro de su política de salud pública.

2. Como podrá apreciar el lector, se trata de un caso donde hay un debate científico médico, en el sentido si tal método anticonceptivo impide la implantación de un óvulo fecundado y los efectos sobre el endometrio.

3. En la STC No.7435, se puede apreciar una situación inusual. El Tribunal Constitucional solicitó a algunas iglesias su postura sobre los efectos de la "anticoncepción oral de emergencia”. Por ejemplo, la Iglesia Católica haciendo referencia a una Encíclica Papal, se opone a cualquier método anticonceptivo y de manera sorprendente indica que la anticoncepción y el aborto son frutos de la misma planta. Y se opone a que el Estado distribuya los anticonceptivos, porque "actúan en realidad como abortivos en las primerísimas fases de desarrollo de la vida del nuevo ser humano”.

4. Lo peor que puede hacer un juez es convocar a los dogmas en asuntos que la respuesta solo puede venir de parte de la ciencia. Poner en una decisión la posición de las iglesias frente a la de los científicos, es como regresar a la época de Galileo en la que la ciencia se enfrentaba a la religión y sufría las consecuencias de la Inquisición.

5. Finalmente, el Tribunal Constitucional tuvo en consideración las posiciones científicas expuestas por la Organización Mundial de la Salud, el Colegio Médico del Perú y el Ministerio de Salud. Sobre ello cabe destacar lo siguiente: "la evidencia científica actual ha establecido claramente que los mecanismos de acción de la anticoncepción hormonal oral de emergencia impiden o retardan la ovulación e impiden la migración de 
los espermatozoides por espesamiento del moco servical. Por tanto, actúan antes de la fecundación (...).Se ha probado que tales mecanismos no tienen acción adversa sobre el endometrio, por lo que no se puede asignar efecto abortificante a la anticoncepción hormonal oral de emergencia".

6. Como se trató de un proceso de cumplimiento, en el que se solicitaba que el Estado, a través de Ministerio de Salud, garantice la provisión gratuita e información sobre el anticonceptivo oral de emergencia (AOE); el Tribunal Constitucional consideró que la AOE sí es un método válido de anticoncepción y que debe estar a disposición gratuita de las ciudadanas y ciudadanos. Es decir, que los efectos de la AOE no son abortivos.

7. No pasaron más de tres años para que el Tribunal Constitucional conociera nuevamente este debate, y fruto de ello en un proceso de amparo asumió una posición distinta a través de la Sentencia No.02005-2009.

8. En la referida Sentencia, el Tribunal Constitucional admite que se ha aportado al proceso abundante información científica. Pero, que ésta información le ha generado incertidumbre; y pese a ello, está en el deber de resolver y asumir una posición respecto de la llamada AOE o "píldora del día siguiente".

9. En la STC No.02005 el Tribunal Constitucional tomó en consideración lo que los laboratorios fabricantes del producto indicaban en los "insertos". Se analizaron cinco productos que eran comercializados en nuestro país y en todos ellos se encontró un común denominador: referido al "tercer efecto". Es decir, que además de inhibir la ovulación o espesar el moco servical, previenen, interfieren o impiden la implantación.

10. De igual modo revisaron la posición de la FDA, respecto de los anticonceptivos de emergencia, y específicamente el producto Plan B. Esta información científica del máximo organismo norteamericano coincide en indicar que la AOE puede inhibir la implantación por alteración del endometrio, según el Tribunal Constitucional. 
11. Es por esas razones que el Tribunal Constitucional, decidió aplicar el principio precautorio en el caso concreto. En el fundamento 47 se indicó lo siguiente: "Junto a los principios que nos han servido de pauta interpretativa respecto al derecho a la vida; para la adopción de una posición respecto de la denominada Píldora del Día Siguiente y su acusada afectación al concebido con el denominado tercer efecto, que produciría cambios en el endometrio y no permitiría la anidación, será necesario utilizar el denominado por la doctrina y la legislación principio precautorio. Esta directriz adquiere especial relevancia en los casos donde se encuentran en controversia la posible afectación de los derechos a la salud y la vida, por actividades, procesos o productos fabricados por el hombre".

12. Demás está decir, que nuestro Tribunal Constitucional para aplicar el principio de precaución, asumió que la concepción y, por ende, la vida se inicia desde el momento en que el óvulo es fecundado por el espermatozoide. Por esas razones declaró fundada la demanda de amparo y en consecuencia ordenó al Ministerio de Salud que se abstenga de desarrollar como política pública la distribución gratuita a nivel nacional de la denominada "Píldora del Día Siguiente".

13. Lo lamentable de ambas decisiones del Tribunal Constitucional, es que no recurrieron a las reglas universales creadas a raíz de los casos Daubert, Joiner y Kumho, para finalmente asumir una posición sólida frente a criterios científicos opuestos.

14. El debate ahora se pondrá más intenso, porque la Corte Interamericana de Derechos Humanos (como lo hemos explicado en este trabajo), ha determinado que la concepción comienza cuando el embrión se implanta en el útero de la madre.

\section{NUESTRO CÓDIGO PROCESAL CIVIL Y LA PRUEBA}

\section{CIENTÍFICA.}

1. Uno de los capítulos que requiere una urgente reforma es el referido a la prueba. De manera especial, el que corresponde a la pericia. 
2. El artículo $264^{33}$, que regula al perito de parte, leído junto con el artículo $263^{34}$, ofrecen un panorama más que confuso. Ambas normas procesales, como vienen siendo interpretadas y aplicadas por nuestros operadores (jueces y abogados), nos indican que si una parte quiere ofrecer una pericia, en su escrito de demanda o reconvención deberá postular tal medio probatorio indicando los puntos sobre los que versará el dictamen, la profesión u oficio de quien deberá practicarlo y el hecho controvertido que se pretende esclarecer con el resultado de la pericia. Pero, no se puede ofrecer el dictamen pericial de parte en el mismo escrito de demanda o reconvención; debiendo esperar que el juez determine su admisibilidad y plazo para su producción. Nada más absurdo.

3. Se atenta contra el derecho a la defensa en su versión más elemental: la de ofrecer el medio probatorio idóneo al momento de demandar o de contestar la demanda o reconvenir.

4. Por ejemplo, si se quiere presentar una demanda de daños y, éstos necesitan ser cuantificados por un contador o economista, se llega al absurdo de que la demanda contenga un "sustento" respecto del tipo de daño producido y el monto al que asciende éste; pero que no sea posible adjuntar a la demanda el respectivo dictamen pericial de parte o informe de experto que lo sustente.

5. Es preciso que la norma procesal sea reformada para permitir a las partes acceder libremente a la prueba pericial, sin necesidad de que el juez en un acto posterior a la demanda, contestación o reconvención, decida su admisión y actuación. Esa libertad probatoria, le puede permitir al juez apreciar el grado de convencimiento que le puede

\footnotetext{
${ }^{33}$ Artículo 264.- Las partes pueden, en el mismo plazo que los peritos nombrados por el juez, presentar informe pericial sobre los mismos puntos que trata el artículo 263, siempre que lo hayan ofrecido en la oportunidad debida.

Este perito podrá ser citado a la audiencia de pruebas y participará en ella con sujeción a lo que el juez ordene.

${ }^{34}$ Artículo 263.- Al ofrecer la pericia se indicarán con claridad y precisión, los puntos sobre los cuales versará el dictamen, la profesión u oficio de quien debe practicarlo y el hecho controvertido que se pretende esclarecer con el resultado de la pericia. Los peritos son designados por el juez en el número que considere necesario.
} 
producir la o las pericias aportadas por las partes $\mathrm{y}$, solo de considerarlo necesario puede ordenar la actuación de una pericia de oficio. Y, no al revés, como actualmente contempla nuestra regulación procesal; que la pericia de parte está condicionada a la que el juez vaya a determinar de oficio.

6. La doctrina procesal denomina a la pericia producida fuera del proceso y aportada en la demanda, contestación o reconvención, como "dictamen pericial extrajudicial”35. De esta manera se prioriza a la pericia de parte, convertida ahora en la modalidad por excelencia de prueba pericial, relegando a un lugar subsidiario y excepcional a la pericia de oficio o de designación judicial.

7. Esta regulación defectuosa, obliga a las partes a realizar "malabares procesales" para presentar en los actos postulatorios prueba científica o técnica. Por ejemplo, postular como "prueba atípica" un informe escrito de experto que contenga una valuación de los daños que sirvan de sustento a una demanda o reconvención. Y, al mismo tiempo, ofrecer una pericia de parte para acreditar el mismo tipo y monto de daño invocado.

8. Un tema aparte radica en el artículo $268^{36}$. Dicha norma solo permite nombrar como peritos, a los que aparecen en el listado que cada colegio profesional proporcione al Consejo Ejecutivo de cada Distrito Judicial. En mi opinión, esta regla procesal restringe severamente el derecho a la defensa de los justiciables, impidiendo, por ejemplo, recurrir a expertos académicos que laboran en universidades de prestigio o, recurrir a expertos internacionales. Demás está indicar, los serios problemas que se presentan por las listas de profesionales que aportan los colegios profesionales, debido a la falta de experiencia, idoneidad y fiabilidad de los peritos nominados.

\footnotetext{
${ }^{35}$ LLUCH, Xavier Abel. La Prueba Pericial, JB Bosch Editor, Barcelona, 2009, pp. 97 y 98.

${ }^{36}$ Artículo 268.- En Consejo Ejecutivo de cada Distrito Judicial, formula anualmente la lista de los especialistas que podrán ser nombrados peritos en un proceso, tomando como base la propuesta alcanzada por cada colegio profesional.

Cuando la pericia no requiera de profesionales universitarios, el juez nombrará a la persona que considere idónea. La misma regla se aplica en las sedes de los juzgados donde no haya peritos que reúnan los requisitos antes señalados.
} 
9. Finalmente, es preciso una regulación especial referida a las pruebas científicas o técnicas, a efecto de que el juez pueda realizar un control de la prueba respecto de su fiabilidad, de los métodos y principios aplicados por el perito o experto y si la aplicación de tales métodos ha sido ejecutada o realizada de forma confiable.

\section{CONCLUSIONES.}

1. La prueba científica es una variante de la prueba pericial, que se caracteriza por la especial idoneidad del experto interviniente. Admite diversas acepciones como prueba pericial propiamente dicha, prueba de peritos, reconocimiento pericial, dictamen de peritos, dictamen de expertos o dictamen de especialistas.

2. Sin perjuicio de lo indicado en el numeral precedente, la prueba científica también puede ser presentada como prueba documental de actuación inmediata. Como se ha podido apreciar de los procesos constitucionales objeto de comentario y de la jurisprudencia de la Corte Interamericana de Derechos Humanos, los jueces pueden recurrir a evidencia científica contenida en artículos de especialidad, informes científicos de organismos internacionales, informes de expertos, etc.

3. No debe confundirse la alta confiabilidad de que goza la prueba científica con la infalibilidad.

4. El juez o árbitro debe actuar como un guardián o gatekeeper de la prueba científica; para evitar que ingrese al proceso (admisión, actuación y valoración), la llamada "mala ciencia" o "pseudociencias".

5. La regla DAUBERT se ha convertido en un parámetro universal, que debiera ser asimilada por nuestra jurisprudencia y legislación.

6. El juez o árbitro debe valorar la correcta realización del procedimiento y la validez del método utilizado. De igual modo, tener en consideración el margen de error. 
7. La ciencia y el derecho ya no pueden seguir caminos separados.

8. Es muy importante replantear la enseñanza del derecho, incorporando estudios elementales de psicología, biología, genética, neurociencia, etc.

9. Los jueces y árbitros deben elevar sus estándares de conocimientos científicos, a fin de que sus máximas de experiencia estén acorde con la sociedad del conocimiento.

10. Es preciso una nueva regulación procesal en materia de prueba pericial. Pero, mientras ello ocurre los jueces no pueden permanecer ausentes al paso de la historia, debiendo adecuar los procedimientos a los nuevos requerimientos de la ciencia y la técnica.

11. Pese a su recepción de manera pacífica por parte de la doctrina continental, los criterios de la regla DAUBERT, en general, no son usados por los jueces o árbitros como herramienta de admisión, actuación y valoración probatoria. Con la honrosa excepción de la justicia penal, que ha dado un paso muy importante en nuestro país, llevando a la prueba científica a un nuevo estándar probatorio.

\section{REFERENCIAS BIBLIOGRÁFICAS:}

CUELlO IRIARTE, Gustavo. Derecho Probatorio y Pruebas Penales, LEGIS, Bogotá, 2008.

ESTUPINYÁ, Pere. El ladrón de cerebros. Compartiendo el conocimiento científico de las mentes más brillantes. DEBOLSILLO, Barcelona, 2013.

GOZAÍNI, Osvaldo. Tratado de Derecho Procesal Constitucional, tomo I, Editorial Porrua, México, 2011. 
LEÓN FLORÍAN, Felipe Johan. Sobre la prueba en el proceso de amparo. En: La prueba en el proceso constitucional. Dialogo con la Jurisprudencia, Guía Práctica 4, Lima, 2010 .

LLUCH, Xavier Abel. La Prueba Pericial, JB Bosch Editor, Barcelona, 2009.

LLUCH, Xavier Abel. La Valoración de la Prueba Científica. En: Derecho Probatorio Contemporáneo. Prueba Científica y Técnicas Forenses. Coordinadora: BUSTAMANTE RÚA, Mónica María, Universidad de Medellín, Fundación Universitaria Tecnológico Comfenalco, Colombia, 2012.

MARINONI, Luis Guilherne. El Derecho Fundamental de acción en la Constitución brasileña. En: Boletín Mexicano de derecho comparado No.123, UNAM, México, 2008.

MIDÓN, Marcelo Sebastián. Pericias Biológicas, Ediciones Jurídicas Cuyo, Mendoza Argentina, 2005.

MOLINA GALICIA, René. Neurociencia, Neuroética, Derecho y Proceso. En: Neurociencia y proceso judicial, Directores: TARUFFO, Michele y NIEVA FENOLL, Jordi, Marcial Pons, Madrid, 2013.

MORELlO, Augusto y VALLEFín, Carlos. El Amparo. Régimen Procesal. Librería Editora Platense, La Plata, 1998.

PARRA QUIJANO, Jairo. Manual de Derecho Probatorio. Librería Ediciones del Profesional LTDA. Colombia, 2004.

PEREZ GIL, Julio. El Conocimiento Científico en el Proceso Civil, Tirant lo Blanch, Valencia, 2010.

QUIROGA DE MICHELENA, María Isabel. LA PRUEBA DE ADN. Fundamentos biológicos de la determinación de paternidad y otras aplicaciones médico legales. En: La Prueba de ADN, Cuadernos Jurisprudenciales, Año 4, Número 37, Gaceta Jurídica, Lima, 2004.

SAGÜES, Néstor Pedro. Compendio de derecho procesal constitucional. ASTREA, Buenos Aires, 2009.

SANDERS, Joseph. La paradoja de la relación metodología y conclusión y la estructura de la decisión judicial en los Estados Unidos. En: Derecho Probatorio Contemporáneo. Prueba Científica y Técnicas Forenses. Coordinadora: BUSTAMANTE RÚA, 
Revista Eletrônica de Direito Processual - REDP.

Rio de Janeiro. Ano 11. Volume 18. Número 3. Setembro a Dezembro de 2017

Periódico Quadrimestral da Pós-Graduação Stricto Sensu em Direito Processual da UERJ

Patrono: José Carlos Barbosa Moreira. ISSN 1982-7636. pp. 04-44

www.redp.uerj.br

Mónica María, Universidad de Medellín, Fundación Universitaria Tecnológico

Comfenalco, Colombia, 2012.

SERRA, María Mercedes. A propósito del rechazo in limine en el amparo. En: El Amparo

Constitucional, Directores: BIDART CAMPOS, Germán y SAGÜES, Néstor, Depalma, Argentina, 1999.

TARUFFO, Michele. La Prueba. Marcial Pons, Madrid, 2008.

VASQUEZ ROJAS, Carmen. De la prueba científica a la prueba pericial. Marcial Pons, Madrid, 2015. 